\title{
Experimental Investigation of the Effect of Tilt Angle on the Dust Photovoltaic Module
}

\author{
Tariku Negash, Tassew Tadiwose \\ Department of Mechanical Engineering, Debre Markos University, Debre Markos, Ethiopia
}

Email address:

thismuch@ymail.com (T. Negash)

To cite this article:

Tariku Negash, Tassew Tadiwose. Experimental Investigation of the Effect of Tilt Angle on the Dust Photovoltaic Module. International Journal of Energy and Power Engineering. Vol. 4, No. 4, 2015, pp. 227-231. doi: 10.11648/j.ijepe.20150404.15

\begin{abstract}
This research paper investigate the effect of tilt angle on the accumulation of dust PV module on energy production and presents a module for predicting soiling losses for eight different tilt angle $\left(0^{0}, 5^{0}, 11.6^{0}, 15^{0}, 21.5^{0}, 25^{0}, 30^{\circ}\right.$ and $35^{\circ}$ ) including the latitude of Bahir Dar city $\left(11.6^{\circ}\right)$ and $21.5^{\circ}$ tilt angle of $10 \mathrm{Kw}$ hybrid solar power plant PV module which is currently installed in Bahir Dar university. The study has shown that during the experimental investigation period there was total loss of insolation due to soiling was $32.32 \%$ and $4.8 \mathrm{KWh} / \mathrm{m}^{2}$ total energy has been absorbed at $0^{\circ}$ tilt angle. Modules at $11.6^{\circ}$ and $21.5^{\circ}$ tilt angles the total insolation loss were $21.92 \%$ and $16.78 \%$ respectively since it has been covered with dust. Approximately both modules have $5.3 \mathrm{KWh} / \mathrm{m}^{2}$ of energy has been absorbed. However, at $25^{\circ}$ tilt angle had a least insolation loss and largest amount of energy absorbed when compared to the remaining seven different tilt angles; it has only $10.77 \%$ of insolation loss and $5.7 \mathrm{KWh} / \mathrm{m}^{2}$ of energy has been absorbed. The remaining tilt angles of $5^{\circ}, 15^{\circ}, 30^{\circ}$ and $35^{\circ}$ the total insolation loss were $25.45 \%, 19.08 \%, 14.20 \%$, and $12.54 \%$ respectively, and also the total energy of $5.08 \mathrm{KWh} / \mathrm{m}^{2}$, $5.52 \mathrm{KWh} / \mathrm{m}^{2}, 5.2 \mathrm{KWh} / \mathrm{m}^{2}$ and $4.59 \mathrm{KWh} / \mathrm{m}^{2}$ were absorbed respectively. Thus, soiling effect has present at any tilt angle, but the magnitude is evident: the flatter the solar module is placed the more energy it will lose.
\end{abstract}

Keywords: Solar PV, Soiling, Tilt Angle, Insolation Loss

\section{Introduction}

A solar Photovoltaic is a method of generating electrical power by converting the solar radiation into direct current electricity using semiconductors that exhibit the photovoltaic effect [1].Photovoltaic system installation has played a big role in renewable energy because PV systems are pollution free, economically reliable for long-term operation and secure energy source. The major obstruction of PV technology is its high capital costs comparedto conventional energy sources and also it is the more widely used technology all over the world; there is $100 \mathrm{GW}$ of solar PV now installed in our world $[2,3]$.

It is estimated that a total of some $5.3 \mathrm{MWp}$ of $\mathrm{PV}$ is now in use in Ethiopia.In April 2012 Ethiopia has established the first Polycrystalline solar PV module assembly plant with the cooperation of SKY Energy International, Metals and Engineering Corporation (METEC) and an Ethiopian state enterprise. The plant would expected to achieve $20 \%$ of Ethiopian power capacity coming from solar energy within the next five years including 3Million solar home systems distribution plan and may also be exported to a neighboring country [4]. Performance of these solar-photovoltaic (PV) system not only depends on its basic electrical characteristics; maximum power, tolerance rated value of percentage, maximum power voltage, maximum power current, opencircuit voltage (Voc), short-circuit current (Isc), maximum system voltage, but also is negatively influenced by several obstacles such as ambient temperature, relative humidity, dust storms and suspension in air, shading, global solar radiation intensity, spectrum and angle of irradiance [5].The radiation received by cells in the PV module is lower than radiation reaching the module surface. The main causes of these energy difference are dirt accumulation on the surface of the modules, reflection and absorption losses by the materials covering the cells and the tilt angle of the PV module. To better understand the effect of tilt angle on soiling, one has to know how it affects the current of the PV modules as it is directly proportional to the irradiance reaching the solar cells. The incident irradiance on PV cells 
inside a PVmodule and the operating temperature of PV cells primarily dictate the power output of module. On a dual axis tracker, when module surface and the incident light rays are perpendicular to each other, the power output will be the highest. Therefore, this study aims to provide a better understanding of the extent at which tilt angle affects the dust, and hence the performance, of PV modules.

\section{Methodology}

\subsection{Description of the Study and Set up of the PV Module}

Bahir Dar city is located at latitude of $11^{\circ} 36^{\prime} \mathrm{N}$ and longitude of $37^{\circ} 23^{\prime} \mathrm{E}$ respectively, and an elevation of 1,840 meters above sea level. [6]. Fig 1 shows four modules that, two modules were dirt and tilt different two angles and the other two modules were clean by washing water and detergent and tilt similar to the two dust modules. And also due to the location of Bahir Dar those four modules face towards south by using compass, since more near to the equator and the system were installed at a minimum height of 1.5 meter from the ground.

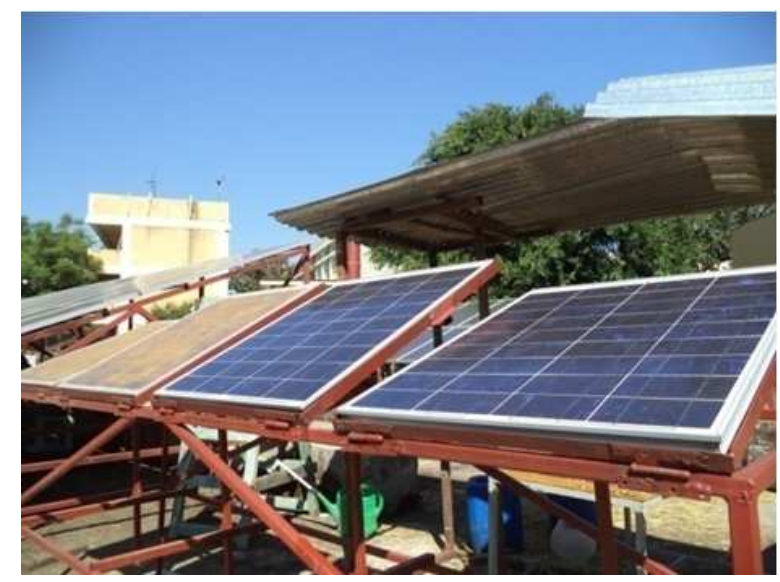

Fig. 1. Clean and dust PV module at 21.50 and 250 tilt angle.

\subsection{Calibration and Linearitycheck of the PV Module}

The international Electronic Commissions (IEC) 60904-10 standard describes the procedures utilized for determination of the degree of linearity of any photovoltaic device parameter in relation to a test parameter. A device is linear when it meets the requirements of IECat section 7.3, which is stated as follows. When some device is claimed to be linear, the applicable range of irradiance, voltage, temperatures, or other necessary conditions should also be stated. The requirements for the acceptable limits of non-linearity (variation) are:

a. For the curve of short-circuit current versus irradiance, the maximum deviation from linearity should not exceed $2 \%$.

b. For the curve of open-circuit voltage versus the irradiance logarithm, the maximum deviation from linearity should not exceed $5 \%$.

c. If the temperature coefficient of short circuit current doesn't exceed $0.1 \% /{ }^{\circ} \mathrm{K}$, the device can be regarded as linear in relation to this parameter $[7,8]$.

During the outdoor experiment, the temperature and the output voltage of all the modules were recorded simultaneously every 15 minute using a multi-meter and a digital thermometer. As well as the irradiance and the short circuit current flow that analysed the linearity of the experiment.

\subsection{Properties of Dust Based on the Laboratory Testing}

Due to small diameter and less density of dust, can be blows in the environment with natural force. This dust diameter that flows on Bahir Dar city that estimatesaround 0.5-150 microns [9]. However it will vary from place to place. Thus, the average particle diameter is used for this experiment by sieving the dust with diameter of $0.075 \mathrm{~mm}$ and it distributed 25 gram amount of dust to each tilt angle of PV module to make dirty.

\subsection{Hydrometer Analysis: Composition of the Finer Dust Particles}

According to ASTM D 422 claysare defined as particles diameter of between $0.075 \mathrm{~mm}$ to $0.005 \mathrm{~mm}$ and silt particles less than $0.005 \mathrm{~mm}$ in diameter. Thus, from the 50 gram sample test of dust silt and clay amount were $63.62 \%$ and $36.38 \%$ respectively. Fig 2 shows that percentage of finer versus grain size diameter $(\mathrm{mm})$.

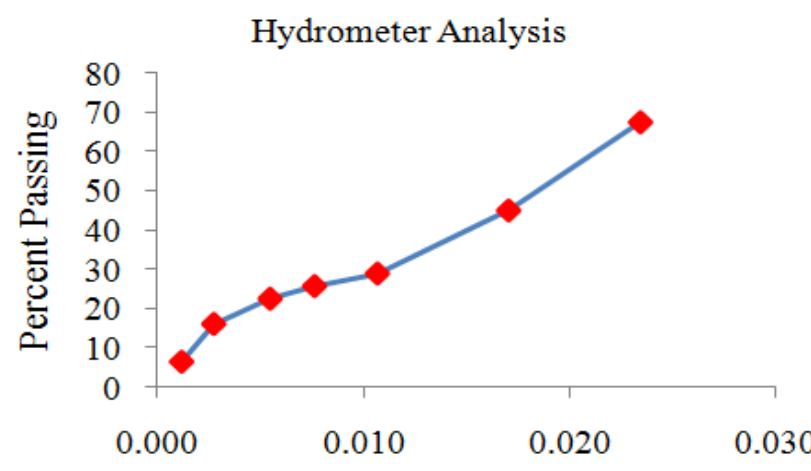

Partilce Size, $\mathrm{mm}$

Fig. 2. Hydrometer analysis of percentage of passing versus diameter of particle size.

\subsection{Experimental Set up and Data Collecting of Wind Speed}

The vantage pro 2 instrument as shown below on Fig 3 that has been used to measure the weather condition of the environment (solar radiation, rainfall, etc). But, for this experiment it is only used to measure the wind speed of the environment close to the PV module installed. The instrument has been installed $2.5 \mathrm{~m}$ away from the PV and at an average height of $1.7 \mathrm{~m}$. The wind data has been stored in the data logger of the wireless vantage pro 2 (Fig 4) devices and export the record data by connecting USB cable to the 
personal computer. The wind speed and direction data were record for eight days within 30 minutes time interval. During this time the tilt angles are changed in two days interval.

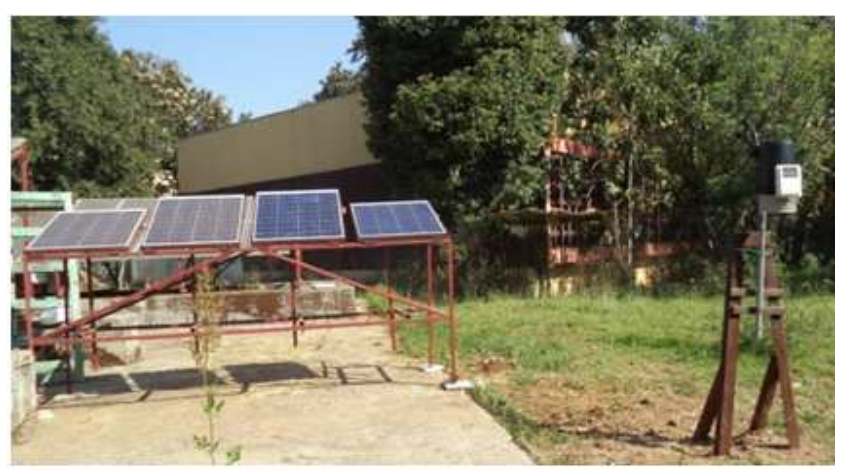

Fig. 3. Set up of vantage pro2 with clean and dusty PV module.

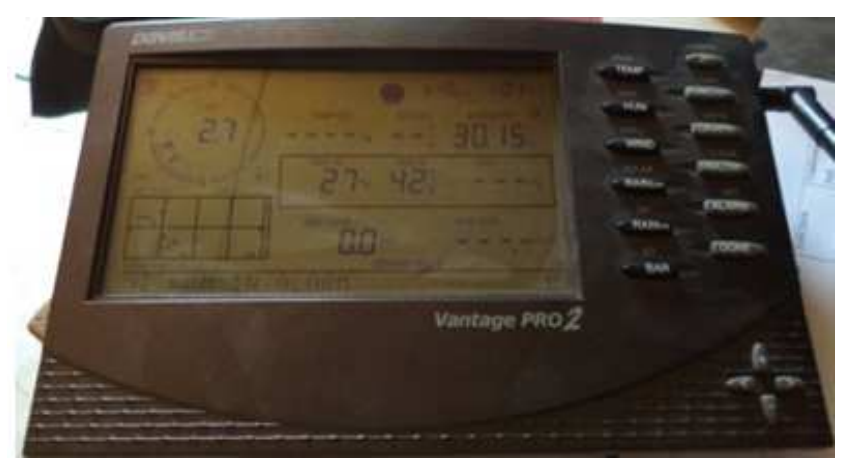

Fig. 4. Wireless data logger.

\subsection{Data Collecting System and Period of Experiment}

On this outdoor experiment, a systematic series of measurements were conducted for several time periods corresponding for eight different tilt angles on soiling and clean PV. The experimental data collection was carried out, for 32 days (September 12 to October 16/2013) excluding the holiday and uncomfortable weather condition. Through those days the experiment was conducted before and after rainfall condition. Particularly, the performance of the clean pair panel was compared with the corresponding of the soiled pair panels under different tilt angle for four days each. The experiment was mostly measured under clear sky, and different atmospheric conditions (e.g. ambient temperature, humidity, wind velocity etc.), for 1 hour there were 4 measurements recorded (approximately one measurement per 15 minute). During the recording procedure the values of the current and voltage of the PV-panels were recorded along with the values of the ambient temperature and solar radiation $(\mathrm{W} / \mathrm{m} 2)$. The loss of energy conversion efficiency can be calculated using the equation (1).

$$
E_{\text {loss }}(\%)=\frac{E_{c, \max }-E_{d, \max }}{E_{c, \max }}
$$

Where: $-E_{c, \text { max }}$ : Energy of clean PV, $E_{d, \text { max }}$ : Energy of dust $\mathrm{PV}$ and, $E_{\text {loss }}(\%)$ : Percentile insolation loss.

\section{Experimental Results Analysis and Discussion}

\subsection{Effect of Tilt Angle Before Rainfall}

As shown in Fig 5, as the tilt angles becomes increasingly from the horizontal surface, the insolation loss or soiling effect increases. Energy losses was varied from $31.24 \%$ to $38.40 \%$ with $0^{0}$ title angle (horizontal) solar modules. For the latitude of $11.6^{\circ}$ energy loss is not as high, but still varied up to $24.68 \%$, depending on the daylight conditions, the amount of dust it has been accumulating soil before rainfall. The $25^{0}$ tilt angle of the PV module highly decreased the insolation loss from $17.56 \%$ to $13.14 \%$ than others of tilt angles and it absorbed high amount of energy through 4 days measurement, $1518.80 \mathrm{Wh} / \mathrm{m}^{2}$ and $1298.03 \mathrm{Wh} / \mathrm{m}^{2}$ on the clean and soiled PV module respectively. Fig. 6 illustrated that unexpected increasing of insolation losses at $30^{\circ}$ and $35^{\circ}$ tilt angleswere conducted since there was Agro-stone dust particles are blowing on the environment near to the experiment site. For angle of $0^{0}, 5^{0}$ and $11.6^{0}$ energy harness is very low but they have large insolation losses.

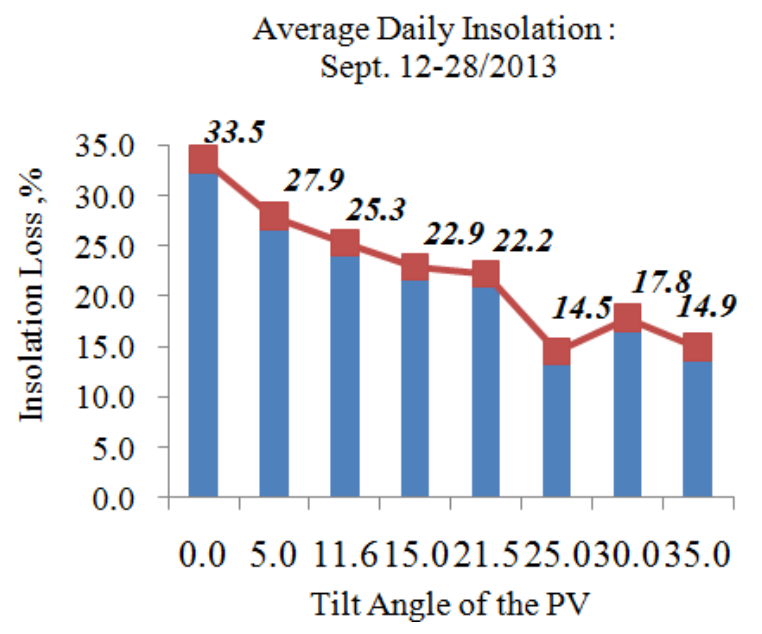

Fig. 5. Average Daily Insolation loss for each tilt angle: Sept12-28/2013.

Total Energy Absorbs Before Rainfall

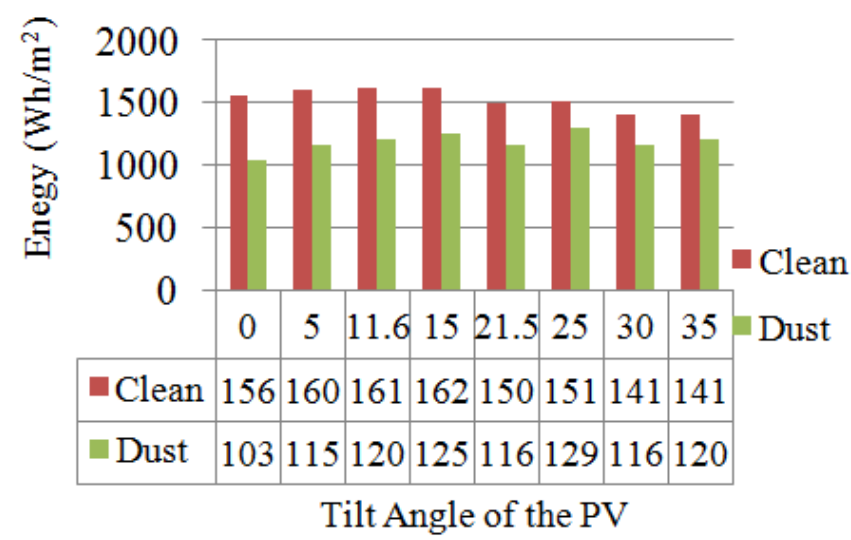

Fig. 6. Total Daily Energy for clean and unclean solar PV before rainfall. 


\subsection{Effect of Tilt Angle After Rainfall}

During this study from Sept 29- Oct16/2013, there was rainfall from $0.2 \mathrm{~mm}$ to $34.5 \mathrm{~mm}$ based on Bahir Dar city weather station data, and it did effectively clean the solar modules from dirt accumulation. However, when there was only $1 \mathrm{~mm}$ of rainfall or less and no wind, it made the soiling effect much worse. Rainfall makes a difference, because rain can act to clean the modules.

As shown on Fig. 7 and 8, the insolation losses decreased linearly up to the $25^{\circ}$ of tilt angle. Within $12.9 \mathrm{~mm}$ average rainfall the drop energy a conversion loss for both the latitude $\left(11.6^{\circ}\right)$ and $15^{\circ}$ tilt angle were decreasedfrom $19.24 \%$ to 16.83 $\%$ and from $15.89 \%$ to $13.67 \%$ through 4 day incessantly measurement respectively. However, with in $8.0 \mathrm{~mm}$ rain fall from Oct.6 to Oct.9 for $21.5^{\circ}$ and $25^{\circ}$ tilt angle the energy losses were decreased from $11.26 \%$ to $9.67 \%$ and $7.17 \%$ to $5.61 \%$ respectively. Beside this, the drop of energy loss are low at $30^{\circ}$ and $35^{\circ}$ of tilt angle even if the tilt angle is high. This illustrates that the soiling effect on PV modules needs more work for long period of time that helps to quantify its effect.However, the rainfall that clean the dust PV modules, still there are insolation loss particularly at small tilt angles.

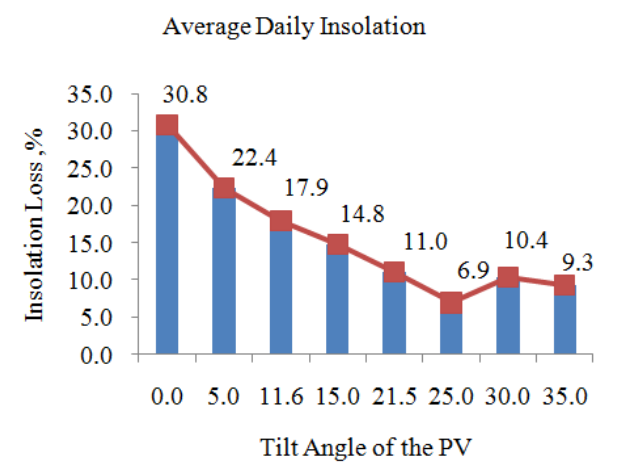

Fig. 7. Average Daily Insolation losses for each tilt angle: Sept.29-Oct. 16/2013.

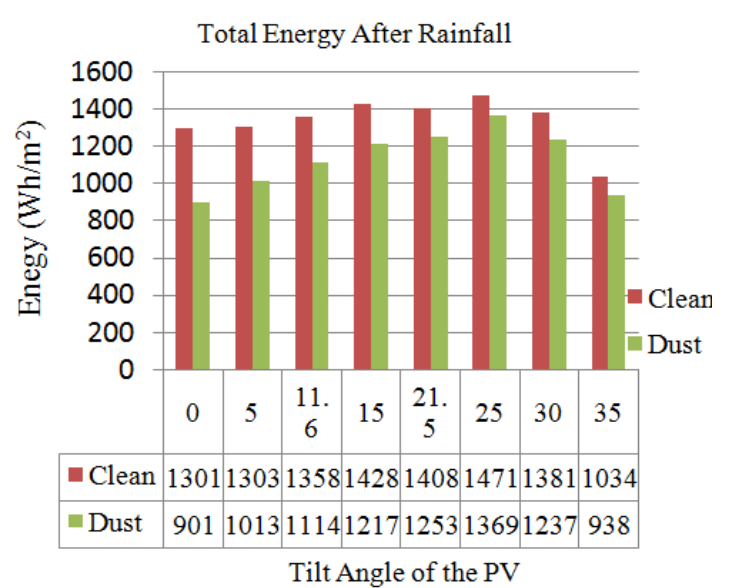

Fig. 8. Total Daily Energy absorbed for clean and unclean solar PV before rainfall.

\subsection{Effect of Tit Angle Both Before and After Rainfall}

To compare the insolation losses before and after the rainfall, the averages were calculated four days each for before and after the rainfall. Fig. 9bars represent a percentage loss of insolation between clean and soiled solar PV module before and after rainfall. The percentage differences of the insolation loss of before and after rainfall were: $2.80 \%$ and $11.18 \%$ at $0^{\circ}$ and $21.5^{\circ}$ tilt angle: that is the least and the highest value out of the entire tilt angle respectively.

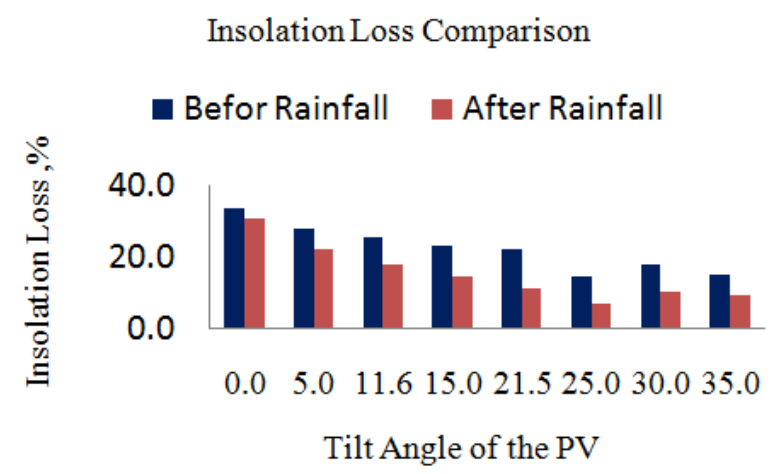

Fig. 9. SoilingComparisononbeforeandafterrainfall from Sept.12/2013Oct16/2013.

\subsection{Effects of Wind Load on a Dust Pv Module}

As illustrated the above fig. 10the wind load has less effect at $0^{0}$ and $5^{0}$ tilt angle to clean the dust PV module due to this there were least energy absorbed difference are shown. As increased the tilt angle the wind load has a power to blown the dust from PV module. Likewise, the amount of the energy absorbed increase as increase number of days. However, the two days variation of energy absorbed were large at $30^{\circ}$ and $35^{\circ}$ tilt angle the amount of energy absorbed as much as expected. This is due to large tilt angle of the dust PV module.

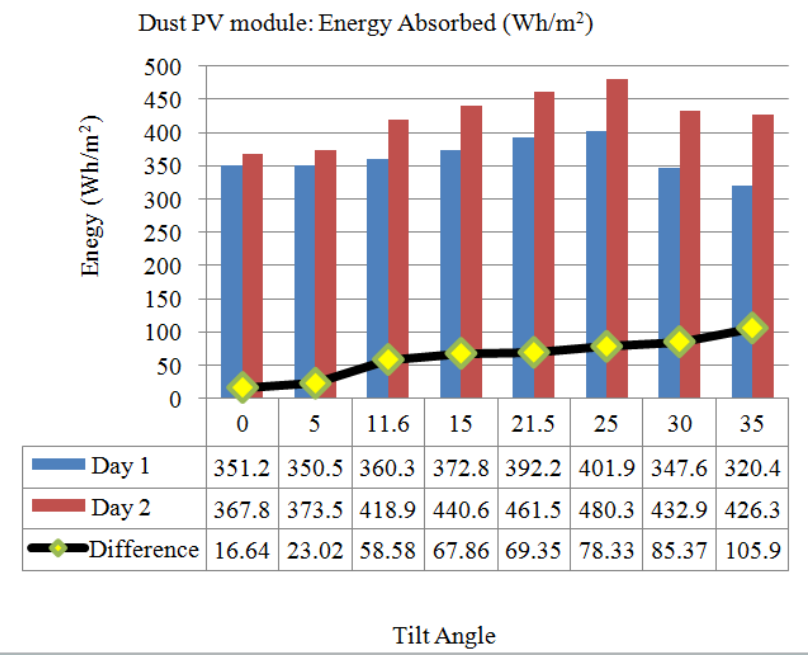

Fig. 10. Effect of wind load on a dust PV module.

\subsection{Selected Tilt Angles Comparison Before and After Rainfall}

Three different angles have been selected to compare the insolation loss at different rainfall amount of each tilt angle, 
for instance: horizontal surface $\left(0^{0}\right)$, latitude of Bahir Dar city $\left(11.6^{\circ}\right)$, and the $10 \mathrm{KW}$ hybrid solar power plant of tilt angle in Bahira Dar University $\left(21.5^{\circ}\right)$. On Fig. 11 the insolation loss can be calculated by interpolated the measured rainfall data between upper and lower value of the insolation loss. This helps to quantify the direct relationship of amount of rainfall to the insolation loss. The insolation loss for each tilt angle at the $0 \mathrm{~mm}$ of rainfall was calculated the average total insolation loss of before rainfall. Thus at zero millimeter of rainfall the insolation loss was $33.59 \%, 25.29 \%$ and $22.21 \%$ at $0^{\circ}, 11.6^{\circ}$ and $21.5^{\circ}$ tilt angle. On the day six the insolation loss was increased linearly at $11.6^{\circ}$ and $21.5^{\circ}$ during the 2 $\mathrm{mm}$ of rainfall. However, the insolation loss was decreased highly at the maximum of the rainfall of $16 \mathrm{~mm}$ that was $29.62 \%, 17.21 \%$ and $9.73 \%$ at $0^{\circ}, 11.6^{\circ}$ and $21.5^{\circ}$ tilt angle respectively.

Daily Interpolated Insolation Loss

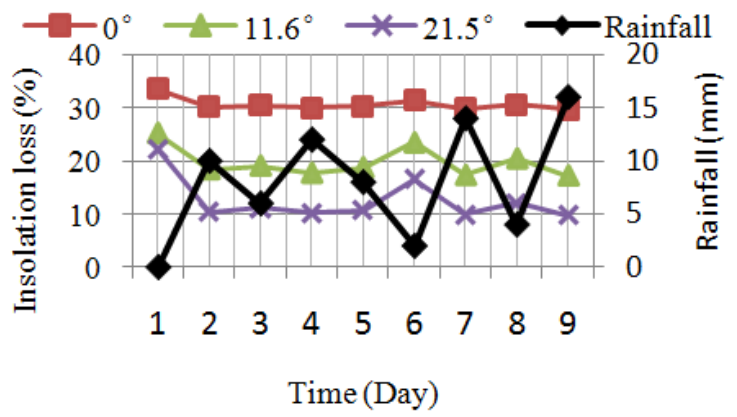

Fig. 11. Daily Interpolated Insolation Loss at different estimated rainfall.

\section{Conclusion}

The outdoor experimental result reveals that, for horizontal surface $\left(0^{0}\right)$ tilt angle, there was a total loss of $32.32 \%$ due to dust and around $4.8 \mathrm{KWh} / \mathrm{m}^{2}$ total energy absorbed. Likewise the study showed that, for $11.6^{\circ}$ and $21.5^{\circ}$ tilt angles the total insolation losses were $21.92 \%$ and $16.78 \%$ respectively because of dust, but they have almost similar energy gained around $5.3 \mathrm{KWh} / \mathrm{m}^{2}$. This implied that the $11.6^{\circ}$ and $21.5^{\circ}$ tilt angles had a lower insolation loss than the horizontal surface tilt angle but large amount of energy was absorbed. However, at $25^{\circ}$ tilt angle had a least insolation loss and largest amount of energy absorbed when compared to the remaining seven different tilt angles; it was only $10.77 \%$ of insolation loss and $5.7 \mathrm{KWh} / \mathrm{m}^{2}$ of energy was absorbed. The remaining tilt angle wherefor $5^{\circ}, 15^{\circ}, 30^{\circ}$ and $35^{\circ}$ the total insolation loss were $25.45 \%, 19.08 \%, 14.20 \%$, and $12.54 \%$ and also the total energy absorbed were $5.08 \mathrm{KWh} / \mathrm{m}^{2}, \quad 5.52 \mathrm{KWh} / \mathrm{m}^{2}$, $5.2 \mathrm{KWh} / \mathrm{m}^{2}$ and $4.59 \mathrm{KWh} / \mathrm{m}^{2}$ respectively. Thus, the dust effect has been present at any angle, but the magnitude is varied: more energy will lose, when the solar modules flatter angle. Nevertheless, the effect of tilt angle on the dust is depending on the environmental condition.

\section{References}

[1] PVeducation.org/pvcdrom/introduction/solar-energy.

[2] JasimAbdulateef. Simulation of Solar Off- Grid Photovoltaic System for Residential Unit. International Journal of Sustainable and GreenEnergy. Special Issue: Engineering Solution for High Performance of Solar Energy System. Vol. 4, No. 3-1, 2014, pp. 29-33.

[3] Solar Power Information (2009, 8 April 2011).'Solar Panels' www.solarpower2day.net/solar-panels/.

[4] Ethiopian Resource Group (2011): National Energy Network: Energy for Growth and Transformation

[5] Salih Mohammed, Osama Ibrahim, KaleidWaleed. Performance Enhancement of PV Array Based on Water Spraying Technique. International Journal of Sustainable and green Energy. Vol. 4, No. 3-1, 2015, pp. 8-13.

[6] http://en.wikipedia.org/wiki/Bahir_Dar 2014.

[7] IEC 60904-10, International Electrotechnical Commission, Photovoltaic devices: Methods of Linearity measurement. 2011

[8] Shaharian A. and Sulaiman, effect of dust on the performance of P module, Malaysia, 2011

[9] AssefaDerebeZegeye, 'Assessment of Upland Erosion Processes And Farmer's Perception Of Land Conservation In Debre-Mewi Watershed, Near Lake Tana, Ethiopia', Cornell university May 2009' 